\title{
Title: Current Atlantic Meridional Overturning Circulation weakest in last
} millennium

\author{
Authors: L. Caesar ${ }^{1,2 *}$, G. D. McCarthy ${ }^{1}$, D. J. R. Thornalley ${ }^{3}$, N. Cahill ${ }^{4}$, S. Rahmstorf ${ }^{2,5}$
}

\section{Affiliations:}

${ }^{1}$ Irish Climate Analysis and Research Units (ICARUS), Department of Geography, Maynooth University, Maynooth, Ireland.

${ }^{2}$ Potsdam Institute for Climate Impact Research (PIK), Member of the Leibniz Association, P.O. Box 6012 03, D-14412 Potsdam, Germany.

${ }^{3}$ Department of Geography, University College London, London, UK.

${ }^{4}$ Department of Mathematics and Statistics, Maynooth University, Kildare, Ireland.

${ }^{5}$ Institute of Physics and Astronomy, University of Potsdam, Potsdam, Germany.

Abstract - The Atlantic meridional overturning circulation (AMOC)— one of Earth's major ocean circulation systems - redistributes heat on our planet and has a major impact on climate. Here, we compare a variety of published proxy records to reconstruct the evolution of the AMOC since about 400 AD. Taken together these data presents a fairly consistent picture of the AMOC: After a long and relatively stable period follows an initial decline in the AMOC starting in the 19th Century, with a second, more rapid, decline following in the mid-20th Century. Taken together, these data suggest that, during the last decades, the AMOC has been at its weakest state for over a millennium. 
The Atlantic Meridional Overturning Circulation (AMOC) is a major mechanism for heat redistribution on our planet and an important factor in climate variability and change. The AMOC is a sensitive non-linear system dependent on subtle thermohaline density differences in the ocean, and major AMOC transitions have been implicated e.g. in millennial climate events during the last glacial period ${ }^{1}$. There is evidence that the AMOC is slowing down in response to anthropogenic global warming ${ }^{2}$ — as predicted by climate models — and that the AMOC is presently in its weakest state for more than 1000 years ${ }^{3}$. As continuous direct measurements of the AMOC only started in $2004^{4}$, longer term reconstruction must be based on proxy data. In general, there are three different types of AMOC proxies: i) reconstructions of surface or subsurface temperature patterns in the Atlantic Ocean that reflect the changes in ocean heat transport associated with the $\mathrm{AMOC}^{3,5}$; ii) reconstructions of subsurface water mass properties, e.g. the advance of the subpolar vs subtropical slope water, that reflect AMOC changes e.g. ${ }^{6}$; and iii) evidence for physical changes in deep-sea currents, such as those reflected by changes in sediment grain size ${ }^{3}$. As all kinds of proxies are limited in their representation of the AMOC (all three can be influenced to some degree by factors in addition to changes in the AMOC), a combination of all three proxy types is needed to provide robust evidence about the evolution of the AMOC.

Here, using several different and largely independent proxy indicators of the AMOC evolution over the last one hundred to nearly two thousand years, we provide strong evidence that the AMOC decline in the 20th Century is unprecedented and that over the last decades the AMOC is in its weakest state in over a millennium.

The proxies are taken from various locations in the Atlantic or the surrounding land areas (inset of figure 1) and represent either different subsystems associated with the AMOC (like Labrador 
Sea density ${ }^{3}$, the presence of subtropical versus subpolar slope waters along the North American East coast ${ }^{6,7}$ ) or the effect of changes in the Atlantic meridional heat transport associated with the $\mathrm{AMOC}^{2,3,5,8}$, as well as surface ocean productivity changes that have been related to the AMOC $^{9,10}$. The records going the furthest back in time (400 AD) are taken from marine sediments (sortable-silt data ${ }^{3}$, proxy records of subsurface ocean temperatures ${ }^{3}, \delta^{18} \mathrm{O}$ in benthic foraminifera ${ }^{7}, \delta^{15} \mathrm{~N}$ of deep-sea gorgonian corals ${ }^{6}$, relative abundance of certain planktic foraminifera (Turborotalita quinqueloba) ${ }^{10}$ ). The temperature-based AMOC index ${ }^{5}$ on the other hand is based on a Northern Hemisphere land-and-ocean temperature reconstruction that uses a range of terrestrial proxies including e.g. tree rings and ice core data ${ }^{11}$. Data taken from Greenland ice cores (the methanesulfonic acid concentration) furthermore provide an estimate for AMOC related changes in productivity in the subpolar gyre (SPG) region ${ }^{9}$. Most of these records extend into the modern era, for which additional AMOC proxies exist that are based on instrumental temperature records ${ }^{2,8}$.

Despite the different locations, time scales and processes represented by these proxies, they provide a consistent picture of the AMOC evolution since about $400 \mathrm{AD}$ : Prior to the $19^{\text {th }}$ century, the AMOC was relatively stable. A decline in the AMOC, beginning during the $19^{\text {th }}$ century, is evident in all the proxy records (figure 1 left panel). Around 1960 a phase of particularly rapid decline started that is found in several, largely independent proxies. A shortlived recovery is evident in the 1990s before a return to decline from the mid-2000s (figure 1 right panel). All indices additionally show multi-decadal variability, albeit with different amplitudes and frequencies making it questionable whether this is mainly driven by the AMOC. Some of the differences likely relate to the large range in temporal resolution in the proxies (from annual to 50-year binning), while others are likely due to complicating factors, such as 
non-AMOC related influences on a proxy system (e.g. changes in trophic structure of coral's food source in $\delta^{15} \mathrm{~N}$, local fluctuations in circulation impacting single site palaeoceanographic reconstructions, or other controls on subpolar heat content ${ }^{12}$ ). An additional factor may also be that different components of the AMOC respond on different time scales. While the strength of the AMOC, typically measured at $26^{\circ} \mathrm{N}$, has been shown to be correlated to the multi-decadal variability of North Atlantic SST ${ }^{13}$ (suggesting that a large part of this variability in the temperature-based proxies are due to AMOC changes) changes in the deep ocean appear to occur on a different timescale. Therefore, it is unsurprising that for the larger part of the last millennium the multi-decadal variability in the proxies differ.

The strength of this multi-proxy comparison lies in tracing the centennial and longer AMOC evolution. To test whether the reduction in AMOC strength that is seen in all proxy records is significant, a change-point model is fitted to each time series and the data means before and after the change point are compared (see Methods). Assuming, in the first approximation, only a single change point, the model finds a significant reduction in the mean in all but one proxy record (see table 1). The timing of the change point varies in the different proxy series (also due to the different lengths of the time series) but can be sorted into two clusters: one change occurring in the second half of the $19^{\text {th }}$ century and a second change occurring in the $1960 \mathrm{~s}$. To test the significance of differences between different time periods, we divided each time series into 50 year intervals (30 year intervals for the Cheng et al. (2017) data given that the length of the time series is only 64 years and 100 year intervals for the Spooner et al. (2020) data given the coarse resolution of this time series), going backward from the present and we estimated the means and data uncertainty for each of these intervals. The mean of any $50(30,100)$ year interval is assumed to be significantly lower when its uncertainty range does not overlap with the 
uncertainty range of the mean of any other interval. The results show that in 9 of the 11 proxy series the most recent $50(30,100)$ year mean value is significantly lower than any other before (see table 1). In addition, the high-resolution proxies suggest a progressive AMOC decline within that most recent interval.

Together these data consistently show that the modern AMOC slowdown is unprecedented in over a thousand years. Improved understanding of this slowdown is urgently needed. The next step is to resolve which components and pathways of the AMOC have altered, how, and why no small feat, and requiring a community effort that combines observational, modelling and palaeoclimatological approaches.

\section{Methods}

Uncertainties. The uncertainty range represents in all but one case the $2-\sigma$ confidence interval for the individual proxy reconstruction, i.e. for i) the proxy-based surface temperature reconstruction (validated against independent instrumental temperature data) ${ }^{5}$, ii) the subsurface temperature dipole in the Atlantic based on the published uncertainties for age assignment and temperature reconstructions ${ }^{3}$, iii) the $\delta^{15} \mathrm{~N}$ record based on a mixed effect linear model based on year and specimen colony ${ }^{6}$, iv) the sortable silt data that is shown with its full (reduced) procedural error $\left.{ }^{3}, \mathrm{v}\right)$ the $\delta^{18} \mathrm{O}$ data based on analytical reproducibility determined by replicate measurements of internal standard carbonate material ${ }^{7}$, vi) the abundance of $T$. quinqueloba with the uncertainty estimated using a binomial approach ${ }^{10}$, and vii) the marine productivity in the subpolar gyre based on a bootstrapping method ${ }^{9}$. As an upper bound for the $2-\sigma$ confidence interval of the relative change in Atlantic Ocean heat content vs that in the Southern Ocean the confidence intervals for the individual ocean heat content time series, considering among others instrumental errors, methodological choices and data gaps, were simply added ${ }^{8}$. 
For the temperature-based AMOC proxy $^{2}$ the uncertainty in converting this proxy data to an AMOC slowdown is given, not the uncertainty of the temperature data itself. This is based on the relationship between the relative temperature change in the subpolar North Atlantic and AMOC variability in the CMIP5 model ensemble.

Although only this last uncertainty interval considers the spread in the proxy that is unrelated to the AMOC, the other proxies have all been related to AMOC variability. Moreover, given that the proxies were taken from multiple locations across the Northern Hemisphere and the only inferred common driver for them all is AMOC, combined, they provide strong evidence for a centennial decline related to the AMOC.

Statistical significance. To determine whether there has been a significant change in the proxy time series that would indicate a reduction in AMOC strength we tested each proxy record for a single significant change in the mean of the time series. Using a Bayesian framework, we fit a model that assumes that the data fluctuate around a constant mean, allowing for a single change in the mean at some point in time. The approach takes both the data uncertainty and the data variability into account. Once the model finds the timing of the change, we compare the means before and after the change point to check if the difference is significant (we assume significance when the $95 \%$ Bayesian credible interval of the difference between the means does not contain a zero value).

To test whether the AMOC is at its weakest in over a millennium we applied a similar framework that fixed change points at $50(30,100)$ year intervals. Starting in the present, the mean and 95\% uncertainty interval for each $50(30,100)$ year interval was estimated (taking data uncertainty and the number of data points in each interval into account). 


\section{Data Availability}

The datasets analysed during the current study were provided by the authors from the original publications (see labels of figure 1). They are available from the corresponding author on request.

\section{Code Availability}

The script for analysing and plotting the data is available from the corresponding author upon request.

\section{Competing Interests statement:}

The authors declare no competing interests.

\section{References:}

1 Rahmstorf, S. Ocean circulation and climate during the past 120,000 years. Nature 419, 207-214, doi:10.1038/nature01090 (2002).

2 Caesar, L., Rahmstorf, S., Robinson, A., Feulner, G. \& Saba, V. Observed fingerprint of a weakening Atlantic Ocean overturning circulation. Nature 556, 191-196, doi:10.1038/s41586-018-0006-5 (2018).

3 Thornalley, D. J. R. et al. Anomalously weak Labrador Sea convection and Atlantic overturning during the past 150 years. Nature 556, 227-230, doi:10.1038/s41586-0180007-4 (2018).

4 Smeed, D. A. et al. The North Atlantic Ocean Is in a State of Reduced Overturning. Geophysical Research Letters 45, 1527-1533, doi:10.1002/2017gl076350 (2018).

5 Rahmstorf, S. et al. Exceptional twentieth-century slowdown in Atlantic Ocean overturning circulation. Nature Climate Change 5, 475-480, doi:10.1038/nclimate2554 (2015).

6 Sherwood, O. A., Lehmann, M. F., Schubert, C. J., Scott, D. B. \& McCarthy, M. D. Nutrient regime shift in the western North Atlantic indicated by compound-specific delta15N of deep-sea gorgonian corals. Proc Natl Acad Sci U S A 108, 1011-1015, doi:10.1073/pnas.1004904108 (2011). 
7 Thibodeau, B. et al. Last Century Warming Over the Canadian Atlantic Shelves Linked to Weak Atlantic Meridional Overturning Circulation. Geophysical Research Letters 45, 12,376-312,385, doi:10.1029/2018g1080083 (2018).

8 Cheng, L. et al. Improved estimates of ocean heat content from 1960 to 2015. Science Advances 3, e1601545, doi:10.1126/sciadv.1601545 (2017).

9 Osman, M. B. et al. Industrial-era decline in subarctic Atlantic productivity. Nature 569, 551-+, doi:10.1038/s41586-019-1181-8 (2019).

10 Spooner, P. T. et al. Exceptional 20th Century Ocean Circulation in the Northeast Atlantic. Geophysical Research Letters 47, e2020GL087577, doi:10.1029/2020GL087577 (2020).

11 Mann, M. E. et al. Proxy-based reconstructions of hemispheric and global surface temperature variations over the past two millennia. Proceedings of the National Academy of Sciences of the United States of America 105, 13252-13257, doi:10.1073/pnas.0805721105 (2008).

12 Keil, P. et al. Multiple drivers of the North Atlantic warming hole. Nature Climate Change 10, 667-671, doi:10.1038/s41558-020-0819-8 (2020).

13 Zhang, R. et al. A Review of the Role of the Atlantic Meridional Overturning Circulation in Atlantic Multidecadal Variability and Associated Climate Impacts. Reviews of Geophysics 57, 316-375, doi:10.1029/2019RG000644 (2019).

\section{Corresponding author}

Correspondence to: Levke Caesar, levke.caesar@mu.ie

\section{Acknowledgments}

L. Caesar, N. Cahill and G. D. McCarthy are supported by the A4 project. A4 (Grant-Aid Agreement No. PBA/CC/18/01) is carried out with the support of the Marine Institute under the

Marine Research Programme funded by the Irish Government, co-financed by the European

Regional Development Fund. D. J. R. Thornalley is supported by UK NERC grant

NE/S009736/1. 


\section{Author contributions}

S.R. initiated the study. L.C. created the figure and wrote the manuscript. N.C. performed the significance testing. All authors discussed and interpreted the results and provided input to the manuscript.

\section{Figure Legends}

\section{Fig. 1: SST-based AMOC reconstructions compared to various proxy reconstructions. a,} The SST-based proxies (light and dark blue) represent the North Atlantic temperature response to changes in the Atlantic meridional heat transport associated with an AMOC slowdown. It is compared to proxy records of $\mathbf{b}$, subsurface ocean temperatures (purple), $\mathbf{c}$ and $\mathbf{h}, \delta^{15} \mathrm{~N}$ data of deep-sea gorgonian corals (magenta), $\mathbf{d}$ and $\mathbf{i}$, sortable-silt data (shades of green, shown with a 12-year lag to the temperature-based indices ${ }^{3}$ ), $\mathbf{e}$ and $\mathbf{j}, \delta^{18} \mathrm{O}$ data in benthic foraminifera (shades of brown), $\mathbf{f}$, the relative abundance of T. quinqueloba in marine sediment cores (orange-red) as well as, $\mathbf{f}$ and $\mathbf{k}$, methanesulfonic acid concentration in Greenland ice cores (orange), both indicators for local/regional marine productivity, and $\mathbf{g}$, the relative change in Atlantic Ocean heat content vs that in the Southern Ocean (dark magenta, only in the right panel). As a reference for the actual change in volume transport the April 2004 - April 2018 linear trend of the RAPID data $^{4}$ (black) is given (g). The map (using the same color-coding as the time series) gives an overview of the various locations the proxies were taken from (with small markers denoting single sites and large markers denoting the areas with multiple proxy sites). All curves were smoothed with a 20-year (50-year) LOWESS filter for the shorter (longer) time series to make them more comparable. Shading and error bars show the $2 \sigma-(95 \%)$-confidence interval of the 
210 individual proxies as they were reported and the uncertainty of the AMOC representation of the

211 Caesar et al. (2018) temperature proxy, respectively (see Methods).

\section{Tables}

\begin{tabular}{|c|c|c|c|c|c|c|}
\hline \multicolumn{3}{|c|}{ General Information } & \multicolumn{2}{|c|}{ Change point testing } & \multicolumn{2}{|c|}{ Significance testing } \\
\hline Proxy & $\begin{array}{c}\text { Time } \\
\text { interval }\end{array}$ & $\begin{array}{l}\text { Long/ } \\
\text { Short }\end{array}$ & $\begin{array}{c}95 \%- \\
\text { interval }\end{array}$ & $\begin{array}{l}\text { Signif. } \\
\text { reduction }\end{array}$ & $\begin{array}{l}\text { Lowest } \\
\text { interval }\end{array}$ & $\begin{array}{r}\text { Signif. } \\
\text { lower }\end{array}$ \\
\hline Temperature anomaly ${ }^{5}$ & $900-1995$ & $\mathrm{~L}$ & 1874-1902 & yes & 1946-1995 & yes \\
\hline $\begin{array}{l}\text { Subsurface temperature } \\
\text { proxy }{ }^{3}\end{array}$ & $400-2000$ & $\mathrm{~L}$ & $1817-1856$ & yes & $1951-2000$ & yes \\
\hline$\delta^{15} \mathrm{~N}$ data ${ }^{6}$ & $1926-2002^{*}$ & $\mathrm{~S}$ & $1970-1976$ & yes & $1953-2002$ & yes \\
\hline Sortable silt data $48 \mathrm{JPC}^{3}$ & $380-1995^{\dagger}$ & $\mathrm{L}$ & $1763-1878$ & yes & $1876-1925$ & no \\
\hline Sortable silt data $56 \mathrm{JPC}^{3}$ & $1475-2003$ & $\mathrm{~L}$ & $1863-1883$ & yes & 1904-1953 & no \\
\hline$\delta^{18} \mathrm{O}$ data $^{7}$ & $708-1962$ & $\mathrm{~L}$ & $1881-1916$ & yes & 1913-1962 & yes \\
\hline T. quinqueloba abundance & $392-2013$ & $\mathrm{~L}$ & $1920-1958$ & yes & $1914-2013$ & yes \\
\hline Temperature proxy $^{2}$ & $1871-2016$ & $\mathrm{~S}$ & $1967-1970$ & yes & $1967-2016$ & yes \\
\hline$\delta^{18} \mathrm{O}$ data $^{7}$ & $1904-2001$ & $\mathrm{~S}$ & $1960-1975$ & yes & $1952-2001$ & yes \\
\hline Marine productivity ${ }^{9}$ & $1767-2013$ & $\mathrm{~S}$ & $1950-1956$ & yes & $1964-2013$ & yes \\
\hline Ocean heat content ${ }^{8}$ & $1955-2019$ & S & $\begin{array}{l}\text { For this data } \\
\text { algorithm di } \\
\text { significant c } \\
\text { point. }\end{array}$ & $\begin{array}{l}\text { set the } \\
\text { honge }\end{array}$ & 1990-2019 & yes \\
\hline \multicolumn{7}{|c|}{$* \delta^{15} \mathrm{~N}$ data starts in $565 \mathrm{AD}$ but is continues only from 1926 onwards. } \\
\hline \multicolumn{7}{|c|}{$\begin{array}{l}+ \text { The last data point of the } 48 \mathrm{JPC} \text { sortable silt data is in } 1995 \text {, but due to robustness for the significance } \\
\text { testing the smoothed data was used which extends only until } 1975 \text { (as this is the penultimate data } \\
\text { point). }\end{array}$} \\
\hline
\end{tabular}

Table 1: Results of the change point and significance testing of the various proxies used to

reconstruct the evolution of the AMOC. The first three columns include general information

about the proxies like the covered time interval and the categorization into long (L) or short (S)

proxy time series. The columns in the middle list the $95 \%$-interval of the change point found by 
217 the change point model with most long time series and most short time series having a change

218 point in the late $19^{\text {th }}$ Century and in the 1960 s, respectively. It is additionally noted whether the

219 reduction in the proxy following the change point is significant. The columns at the right list the

$22050(30,100)$ year interval during which the proxy is at its lowest value and whether this value is

221 significantly low compared to all other $50(30,100)$ year intervals (considering data uncertainty). 